\title{
Malaria endemicity and co-infection with tissue-dwelling parasites in Sub-Saharan Africa: a review
}

\author{
Nyamongo W. Onkoba ${ }^{1,2^{*}}$, Moses J. Chimbari ${ }^{1}$ and Samson Mukaratirwa ${ }^{3}$
}

\begin{abstract}
Mechanisms and outcomes of host-parasite interactions during malaria co-infections with gastrointestinal helminths are reasonably understood. In contrast, very little is known about such mechanisms in cases of malaria co-infections with tissue-dwelling parasites. This is lack of knowledge is exacerbated by misdiagnosis, lack of pathognomonic clinical signs and the chronic nature of tissue-dwelling helminthic infections. A good understanding of the implications of tissuedwelling parasitic co-infections with malaria will contribute towards the improvement of the control and management of such co-infections in endemic areas. This review summarises and discusses current information available and gaps in research on malaria co-infection with gastro-intestinal helminths and tissue-dwelling parasites with emphasis on helminthic infections, in terms of the effects of migrating larval stages and intra and extracellular localisations of protozoan parasites and helminths in organs, tissues, and vascular and lymphatic circulations.
\end{abstract}

Keywords: Malaria, Tissue-dwelling helminths, Zoonosis, Co-infection, Immunomodulation

\section{Multilingual abstracts}

Please see Additional file 1 for translations of the abstract into the six official working languages of the United Nations.

\section{Introduction}

Malaria is a deadly infectious disease and one of the main health problems facing developing countries in Sub-Saharan Africa (SSA) and Asia. Globally, 3.4 billion people are at risk of new malaria infections, and there are around one million deaths annually [1-3]. Plasmodium falciparum, Plasmodium vivax, Plasmodium malariae, Plasmodium ovale and Plasmodium knowlesi parasites infect humans under normal conditions [4] with $P$. falciparum and $P$. vivax being the major species that cause morbidity and mortality in children under five years of age, pregnant women and travellers from non-malarious areas [5, 6].

\footnotetext{
* Correspondence: bwonkoba@gmail.com

${ }^{1}$ College of Health Sciences, School of Nursing and Public Health, University

of KwaZulu-Natal, Howard Campus, Durban, South Africa

${ }^{2}$ Departmet of Tropical Infectious Diseases, Institute of Primate Research,

Karen, Nairobi, Kenya

Full list of author information is available at the end of the article
}

In SSA, morbidity and mortality due to malaria is decreasing despite a lack of a malaria vaccine, emergence of parasite resistance to available anti-malarial drugs, the anopheline mosquito being resistant to insecticide residual spraying and a poor socio-economic situation that hinders malaria control and management [7-9]. Efforts in drug discovery and vaccine development are hindered by limited knowledge of the underlying cellular and molecular mechanisms of host-parasite interactions during co-infection and polyparasitism $[10,11]$. This is also aggravated by the emergence of zoonotic $P$. knowlesi malaria infections [12-14] as well as other zoonotic infectious diseases $[15,16]$. Trichinellosis is an emerging and re-emerging zoonotic disease the geographical distribution of which overlaps with malaria in endemic areas of Tanzania, Uganda, Kenya, Ethiopia, Zimbabwe, South Africa and Mozambique [17-23]. The development of vaccines against parasitic infections has been complicated due to the fact that co-infecting parasites have life cycles that are either direct or complex. Direct life cycles involve cycling of mature parasites from one definitive host to another while complex life cycles involve cycling of distinct developing life stages through a number of intermediate hosts [24]. Parasite cycling within 
intermediate hosts causes trafficking of molecular epitopes resulting in a generation of parasites variant surface antigens and excretory and/or secretory products that act as host immuno-regulators during co-infections and clinical trials, and hinders the understanding of parasite biology [25-36].

Epidemiological studies have shown that the largest burden of malaria infections is felt by communities living in poor regions of developing countries [37-39]. In these areas, high prevalence of soil-transmitted helminthic infections have also been documented [40]. This results in co-infections, multi-parasitism or polyparasitism [41]. In the past three decades, several studies have been undertaken to establish the nature of interaction that occurs between soil-transmitted helminths (STHs) and malaria during co-infection scenarios. The studies have mainly focused on immunological aspects and disease outcomes neglecting non-immunological mechanisms that may explain the heterogeneity observed in these studies [42, 43]. Varying conclusions have been made from both epidemiological studies and laboratory experiments. Some studies have established that helminths may confer protection against cerebral malaria, others indicate that helminths exacerbate malaria, others report a reduction or increase in prevalence and transmission of malaria, while a few others report no association between the parasites [44-47]. The lack of general consensus in the studies is evidence that malaria immunity is not well understood. However, it is argued that STHs influence clinical malaria disease presentation or confer malaria tolerance through the establishment of chronic infections, induction of adaptive immunity [48] and immunosuppression of immune responses to unrelated antigens and parasites [49]. These result in an induction of host regulatory immunity, and signalling and effector mechanisms [50-52] that are beneficial to coinfecting parasites. This is mainly due to host's failure to regulate the immune responses induced by the parasites. During co-infections, one parasite does not have direct influence on disease outcome and establishment of another parasite, however, the concept of parasite-host-parasite interactions plays a key role. One parasite influences the host to induce immune responses that will favour its establishment which in the long run, become beneficial to the coinfecting parasite. This immunological phenomenon is parasite-driven to make the host susceptible to infection and not favour the establishment of the co-infecting parasite. The amelioration or exacerbation of the disease outcome of the co-infecting parasites is a spill-over effect.

In the majority of co-infection studies, tissue-dwelling parasites, prevalent in SSA, have not been adequately considered. The hypothetical arguments presented are sketchy, making it difficult to clearly predict disease outcomes during malaria interaction with tissue-dwelling parasites. In this review, we discuss and summarise the available information and research gaps in studies undertaken on the interactions between malaria and tissue-dwelling parasites.

\section{Review \\ Methods \\ Information sources}

The online bibliographic databases, MEDLINE/PubMed, EMBASE, Web of Science, Cochrane Library and Google Scholar were searched for studies on host-parasite interactions of malaria co-infection with tissue-dwelling helminths (up to May 2015). Bibliographic lists and references of the selected papers and previous reviews were used as leads for identification of additional studies.

\section{Literature search}

The search was conducted using predefined medical subject heading $(\mathrm{MeSH})$ terms, Boolean operators (OR, AND) and truncation symbols used in combinations of direct key words: malaria, protozoa, co-infection, nematodes, tissue-dwelling parasites, cestodes, trematodes, intracellular parasites, helminths AND all permutations of $\mathrm{MeSH}$ terms in all fields.

\section{Study selection}

Studies were included in the review if they explicitly reported on immune responses and disease outcomes during malaria co-infection with: (i) tissue and organ-dwelling parasitic protozoa; (ii) migrating parasitic helminths and protozoa; and (iii) vascular and lymphatic circulation dwelling parasites. One hundred and sixty-eight (168) studies were retrieved from the search of published work, of which 13 were excluded because of duplication and 123 were irrelevant because they were dealing with malaria coinfections and soil-transmitted parasites. Therefore, 32 studies including abstracts, reviews and reports on malaria co-infection with tissue-dwelling parasites were selected and reviewed. No grey literature was included. All articles were managed using Mendeley Desktop reference manager version 1.13.3 (NY, USA). The results of the analysis of the full papers read are described below.

\section{Results}

\section{Migratory helminths and protozoans, and malaria} co-infections

Poor hygiene and sanitary conditions, and dysfunctional health delivery systems in developing countries predispose people living in these areas to STH infections [53, 54]. For example, humans acquire trichinellosis through ingestion of raw or undercooked meat contaminated with infective Trichinella larvae [55], or gastrointestinal helminthiases/ protozoa infection by ingesting food and water contaminated with embryonated eggs/cysts [19, 56, 57]. Some 
STHs and protozoans have complicated life cycles that involve a tissue migration phase where larvae obligately migrate through host vital organs causing tissue damage and myositis [58-61]. The tissue migrating larvae (ML) or protozoa trigger induction of immunomodulation [62] through the release of excretory and/or secretory products that act as natural stimuli for stimulation of type 2 skewed immune responses [63]. The Th2 immune responses abrogate inflammation, delay worm expulsion and initiate tissue repair $[59,64]$. But knowledge of these immunological pathways and signalling are not well described indicating the need for more research to disentangle the underlying immunological scenarios that occur.

Several co-infection studies have been designed and conducted on the assumption that chronic helminths may alter malaria severity and immunity either through Th2/T regulatory lymphocyte immunomodulation, altered antibody dependent cellular inhibition, immunosuppression of proinflammatory activity or presence of cross reactive antibodies [47, 65]. On the contrary, Hoeve et al., (2009) [66] established that $P$. chabaudi malaria parasites are capable of altering Th2 immune responses and initiation of pulmonary tissue repair in BALB/c mice co-infected with Nippostrongylus brasiliensis. This indicates that the presumption that helminths always alter malaria severity and immunity is not always correct. Several laboratory experiments have also shown that malaria parasites are capable of suppressing helminth-associated immunological activation thereby exacerbating pathological outcomes caused by the ML [67]. Therefore, this shows that co-infecting helminths influence the host immunity to mediate immune responses that are beneficial to malaria parasites during co-infection. However, the underlying pathophysiological and immunological mechanisms utilised by co-infecting parasites are not completely understood despite the findings being extrapolated to explain disease outcomes in humans. Therefore, it is imperative that considerations are made on non-immunological aspects of infections such as nutrition, immunological status, vector exposure frequency and population genetics to explain the conflicting results. Furthermore, the varied immunological profiles that are elicited by ML stages in various body compartments need to be considered when explaining concepts of immunomodulation. Establishing an animal model for malaria and tissue-dwelling helminth co-infection is of utmost importance, and the use of Trichinella sp. as the tissue-dwelling helminth is proposed because of its adaptability to laboratory animals as well as its ease of maintenance. For example, studies could be done on the migratory pathways taken by Trichinella sp. and how the Trichinella sp. may ameliorate allergic and autoimmune diseases in mono- and co-infections with malaria $[62,68,69]$. To our knowledge there are no studies that have been undertaken to determine the interaction of Trichinella sp. with tropical infectious diseases. In SSA, although very few human cases have been reported, trichinellosis is considered as an emerging/re-emerging zoonotic disease that has been reported to infect a variety of mammals $[19,20,70]$. Onkoba et al. [71] established that mice co-infected with chronic T. zimbabwensis ameliorate and supress $P$. berghei infection. This is attributable to the comparable levels of interferon gamma (IFN- $\gamma$ ) secreted during co-infection and correlated with protective immunity [72]. However, further research is needed to provide new knowledge and insight into its co-infection with malaria, and the implication on vaccine efficacy and development of diagnostic tools for surveillance and control in case of future outbreaks.

\section{Enteric-dwelling protozoa and malaria}

Intestinal protozoans, Giardia lamblia and Entamoeba histolytica have been reported to be major causes of severe intestinal disorder mostly in children, and HIV/ AIDS and immunocompromised patients [73-75]. The protozoa colonise the intestinal mucosa where they elicit localised innate immune responses against severe forms of the disease [76]. The underlying mechanisms for their unusual migration in the small intestines are still unknown [77].

Coccidian parasites, Isospora belli, Cryptosporidium sp. and Cyclospora sp. also cause severe diarrhoea, morbidity and mortality [78]. Despite this, their actual disease burden and prevalence are underestimated in developing countries due to a lack of patient records and sensitive serological assays for disease detection [76]. In developing countries, prevalence of Cryptosporidium parvum infections are increasing due to environmental contaminations by pets, poultry, domestic animals and infected humans [79-81]. In literature, these enteric-dwelling protozoan parasites are only considered as opportunistic infections that are acquired by children, and HIV/AIDS and immunocompromised patients [82-85]. Their role as potential co-infecting parasites with tropical infectious diseases such as malaria has been neglected despite their prevalence in SSA where malaria is endemic. The risks of potential co-infection of enteric-dwelling parasites with malaria is possible through contaminated drinking and recreational water [86, 87], being in overcrowded households, coming into contact with infected calves and maintaining poor personal hygiene [82]. Enteric-dwelling parasitic infections lack specific therapy and vaccines making control of co-infections with malaria a challenge. Persons co-infected with malaria and enteric parasites are expected to exhibit severe diarrhoea, wasting syndrome and reduced quality of life, resulting in a high morbidity and mortality rate in the young and elderly, as well as immunocompromised patients. Co-infections are possible is SSA because susceptible persons live in environments contaminated with sewage, and also share housing 
with young calves, poultry, cats and dogs that are potential sources of zoonotic transmissions [81, 88].

\section{Blood and tissue-dwelling protozoan parasites}

Transmissions of vector-borne parasitic infections are on the rise due to changes in climate and global trends, human behaviour, vector behaviour and prey/host switching $[85,89]$. The complexity of their life cycles, sophistication in their induction of immune evasion and intricate host-parasite interactions [90] have complicated their diagnosis, drug discovery and vaccine development, as described below:

a) Trypanosomes and malaria: In SSA, the tsetse fly transmits extracellular protozoan parasites cause debilitating human African trypanosomiasis (HAT) and nagana in livestock [91]. The diseases have endemic foci in East, Southern and West Africa where they share the same geographical distributions with malaria and STHs, resulting in co-infections and polyparasitism [92]. Prevalence studies conducted in Kenya, Uganda, Tanzania and Sudan have shown that on average $70 \%$ of HAT patients in these countries are co-infected with malaria and STHs [93-95]. This has made diagnosis and management of HAT difficult because both malaria and HAT have common clinical symptoms: intermittent fever, headache, general body pains, sleep disturbances and coma [96]. Mice concurrently infected with $P$. yoelii or Trypanosoma brucei have been shown to block resistance to Echinostoma revolutum parasite infection. [97]. This suggests that a synergistic interaction exists between protozoan and helminth infections. However, these studies do not provide explicit information on parasite-specific cellular immune and disease outcomes during these interactions, an indication that additional studies are needed. Malaria co-infection with HAT will result in exacerbation of malaria disease outcome with cerebral involvement. Both parasites potentially cross the blood brain barrier and the sequester in microvasculature of the brain resulting in cerebral malaria and eventually coma [91, 94, 98, 99].

b) Babesia sp. and malaria: Due to increased humanwildlife and livestock-wildlife interactions, a severe recrudescence of malaria-like babesiosis in humans and livestock has been reported [100]. In SSA, the actual prevalence and distribution of tick-borne diseases have not been well mapped [101-104]. In humans, Babesia sp. infections might be misdiagnosed as Plasmodium sp. because of their overlapping similarities in symptoms [105-109]. This setback has compromised diagnosis, treatment, management of both diseases and possible development of vaccines $[78,100,108,110]$. During babesiosis infection, the host elicits humoral and cell-mediated immune responses that are responsible for parasite clearance. However, immune-evasion has been suspected during infection [111]. Clark and Jacobson, [112] established that both Babesia and Plasmodium parasites confer crossprotection to mice during co-infection. A human case report from Korea showed that Babesia parasites prolonged severity of malaria-induced haemolytic anaemia during co-infection [113]. A child from Ivory Coast co-infected with Plasmodium sp. and Babesia sp. parasites exhibited markedly enhanced malaria severity [114]. On the other hand, rhesus macaques with chronic $B$. microti infection showed that $B$. microti parasites were able to suppress $P$. cynomolgi infection [115]. Therefore, studies show that B. microti parasites either provoke induction of immune responses that either ameliorates or exacerbates malaria infection. However, these few available studies have not provided enough insight into immunology and cellular mechanisms that are involved during monoand co-infection.

c) Leishmania sp. and malaria: In Sudan and Uganda, Leishmania donovani complex parasites and malaria have been reported to co-infect humans. The co-infections showed a synergistic immunological interaction characterized by enhanced Th1 immune responses $[116,117]$. The $L$. donovani complex parasites naturally colonise macrophages to initiate counter regulation of host immune responses resulting in a release of anergic/dysfunctional T-cells and blocking of intracellular cytokine signalling in macrophages and dendritic cells [116]. Currently, the available information on the interaction of visceral leishmaniasis and malaria co-infections among pastoral communities of Kenya, Uganda and Sudan is limited. It does not provide vital information on disease outcomes and immunological interactions. Malariainfected red blood cells are recognised and internalised macrophages and dendritic cells that are also colonised by Leishmania parasites. This shows that during coinfection the control of malaria will be impaired in that the effector cells are used by the Leishmania parasites for immunoregulation. This will result in the exacerbation of malaria disease and suppression of Leishmania parasites or, conversely, the parasites will impact the host immunity and influence infection and pathophysiological responses of both parasites. The role of Leishmania parasite mediators and vector saliva components in mediating immunosuppression of host regulatory immune responses are still unknown $[118,119]$. Therefore, further research should be undertaken to determine disease prevalence and impact on socio-economic and environmental factors in regions where congruency of the two parasites is eminent.

d) Toxoplasma gondii and malaria: Toxoplasma gondii is a cosmopolitan intracellular apicomplexan parasite that causes ocular, congenital, neurological and systemic infections in approximately one third of the world's population [120-122]. Humans acquire infection through ingestion of sporulated oocysts and trophozoites in undercooked meat, organ transplants from 
infected donors or through vertical transmission during pregnancy [123]. Stray dogs and cats feeding on offal at abattoirs, poor sewerage systems and sanitation standards, and anthropogenic, climatic and socio-cultural factors have been implicated in human outbreaks of $T$. gondii infections $[122,124,125]$. The severity of infection depends on host immunity and inflammatory foci involved [126]. A questionnaire study conducted in Kenya established that sources of drinking water and disposal of cat faeces are infection risks amongst subsistence farmers [127]. However, the protozoan parasite is still regarded as an opportunistic agent and not as a causative agent of major infections $[84,128-130]$. This implies that toxoplasmosis and malaria co-infection cannot be ruled out in this malaria-endemic region. In several mono-infection studies, it has been established that T. gondii and Plasmodium parasites utilise similar cellular mechanisms and biochemical pathways for their nutrition, metabolism, pathology and immunomodulation [131, 132]. This might indicate that during co-infections the parasites will result in competitive establishment that may promote or hamper parasite pathogenicity, and foetal and birth outcomes during pregnancy [133], severity of anaemia and mortality [124, 134-136], and severity of neurological and cerebral involvement [137, 138, 98]. Malaria and Toxoplasma parasites sequester in the placenta resulting in placental disc plate damage thus influencing foetal and pregnancy outcomes [139]. Despite these prospects of fatal disease outcomes there is striking paucity of information on immunological and disease outcomes and interactions during co-infections with $T$. gondii.

\section{Lymphatic-dwelling filarial worms and malaria}

Lymphatic filariasis (LF) caused by Wuchereria bancrofti, Brugia malayi, Onchocerca volvulus and Loa loa are endemic in SSA [140, 141]. The filarial nematode worms and Plasmodium parasites are transmitted by the same anopheline mosquito vector making co-endemicity a common phenomenon [142, 143] This necessitates implementation of integrated control measures [141]. Several studies on chronic LF interactions with malaria have been conducted [140] and have shown that patent filariasis is able to modify immunological balance to confer protection against malaria severity or exacerbate it [144-146]. The amelioration malaria severity is achieved by the combined induction of Th1 and Th2 immune responses with increased interleukin (IL)-5 and IFN- $\gamma$ production $[48,147,148]$. On the other hand, pre-patent filariasis exacerbates malaria severity through immunosuppression of IFN- $\gamma$ and initiation of activation of CD4 + CD25 + FoxP3+ T-regulatory cells [145]. In epidemiological studies, antihelminthic treatment against LF has been shown to reduce LF exposure through interruption of its transmission dynamics $[149,150]$. However, in murine studies, it has been shown to exacerbate malaria and sepsis [151], thus negating its usefulness in malariaendemic areas. On the other hand, Aliota et al. [152] established that filarial worms are capable of reducing Plasmodium parasite infectivity within the mosquito vector. However, these studies have not determined the immunological changes that occur during deworming and its benefits towards integrated control strategies in malariaendemic areas.

\section{Taenia solium, Echinococcus granulosus and E. multilocularis, and malaria}

Larval stages of some tapeworms cause fatal liver, brain and lung metastasis in humans and livestock [153, 154]. In SSA, exposure risks are attributed to changes in human culinary habits $[85,155]$ and environmental contamination by stray dogs and cats [127, 156-158]. The resultant diseases cause physical damage to vital body organs and tissues, and even lead to neurological and cerebral damage [159]. Active infection favours induction of a Th2 skewed immune response characterised by markedly elevated levels of IL-4 and IL-10 [160, 161]. In several areas of SSA, tapeworm infections are rare due to religious and agricultural practices [162]. However, isolated cases of human infections have been reported in people working in commercial pig farms [163, 164], or living in areas where there are no sanitation facilities and the presence of free roaming pigs $[165,166]$. Information on malaria and cestodes infections is non-existent. Therefore, further studies are needed to determine the actual prevalence, disease burdens and even cases of coinfection with malaria.

\section{Trematodes and malaria}

Fasciola hepatica and F. gigantica in humans are emerging infections and occur in malaria endemic areas despite the parasites not being considered to have relevance in malaria co-infections [167-169]. One of the most important and common snail-borne trematode infections in humans is due to Schistosoma haematobium and $S$. mansoni, and these are becoming emerging or reemerging infections in developing countries of SSA due to climate changes that are influencing spatial distribution of fresh water snails $[170,171]$. Therefore, the impact of fascioliasis and schistosomiasis on communities demand rapid action and research to define control measures, transmission patterns and epidemiological situations. There is paucity of data on the interaction of fascioliasis with malaria except for shared zonal distributions in Egypt [172]. Thus, research on the interactions between both parasites in their shared ecoepidemiological settings is required.

Several laboratory experiments and epidemiological studies have been conducted and meta-analysis reviews 
have been done to determine the host-parasite interactions of malaria and schistosomes during co-infection [173]. The studies have shown that clinical outcomes of malaria and immune responses during co-infections with schistosomes are influenced by age, host genetics, immunity and exposure rates in humans [174-181]. In animal models, immunological responses induced also depend on the strain of the parasite and patency of the helminthic infections [182-184]. Research findings show that schistosomes induce Th2 immune responses that are either detrimental or beneficial to the host during co-infection $[177,185,186]$. These findings further show that schistosomes increase malaria susceptibility and transmission [187] but have not been able to conclusively explain the underlying mechanism and pathways for immunomodulation.

\section{Conclusion}

There are few studies that are directed towards elucidating the host-parasite interactions and disease outcomes that are elicited by tissue-dwelling parasites during co-infection with malaria. This has created a glaring paucity of data on understanding the mechanisms and outcomes of tissue-dwelling parasites and mono- and co-infection with malaria. This has also hampered diagnosis, vaccine development, drug discovery, and management and control of these emerging and re-emerging parasites. Therefore, further studies are imperative to address this lack of data and the heterogeneity of results reported during STHs, schistosomes and filarial worm co-infection with malaria. These future studies should be designed and controlled towards elucidating cellular and molecular pathways as well as migratory pathways that are utilised by migrating tissue-dwelling helminths and protozoa. The utilisation of different study designs and approaches, as well as different tissue-dwelling helminths and protozoa will provide vital information that can be extrapolated to humans. These studies and experiments will also provide information on nonimmunological aspects, timing and order of parasite infections. The disease outcomes across broad range of hosts and parasites will show evidence of parasitehost-parasite interactions at the phenotypic level. This data will be useful in explaining the actual cellular and molecular mechanisms and signalling pathways that influence conferring of protective immunity, exacerbation and/or amelioration of disease outcomes that have been observed in concomitant and concurrent infections. In the long term, the studies will provide the thrust for deworming, surveillance, diagnosis, vaccination campaigns and vaccine trials in areas of SSA where tissue-dwelling parasites are co-endemic with malaria.

\section{Additional file}

Additional file 1: Multilingual abstracts in the six official working languages of the United Nations. (PDF $255 \mathrm{~kb}$ )

\section{Abbreviations}

HAT: human African trypanosomiasis; HIV/AIDS: human immunodeficiency virus infection/acquired immune deficiency syndrome; IFN- $\gamma$ : interferon gamma; IL: interleukin; LF: Iymphatic filariasis; MeSH: medical subject headings; ML: migrating larvae; SSA: Sub-Saharan Africa.

\section{Competing interests}

The authors declare that they have no competing interests.

\section{Authors' contributions}

NWO designed the study, conducted the literature search, processed the results and drafted the paper. MJC and SM guided the design, coordinated the search, did the analysis, and drafted and reviewed the paper. All authors read and approved the final paper.

\section{Acknowledgements}

This study received financial support from the College of Health Sciences, University of KwaZulu-Natal through a PhD studentship bursary awarded to NWO.

\section{Author details}

${ }^{1}$ College of Health Sciences, School of Nursing and Public Health, University of KwaZulu-Natal, Howard Campus, Durban, South Africa. ${ }^{2}$ Departmet of Tropical Infectious Diseases, Institute of Primate Research, Karen, Nairobi, Kenya. ${ }^{3}$ School of Life Sciences, University of KwaZulu-Natal, Westville Campus, Durban, South Africa.

Received: 12 May 2015 Accepted: 3 August 2015

Published online: 29 August 2015

\section{References}

1. Casares S, Richie TL. Immune evasion by malaria parasites: a challenge for vaccine development. Curr Opin Immunol. 2009;21:321-30.

2. World Health Organization: World Malaria Report. 2012.

3. Langhorne J, Ndungu FM, Sponaas A-M, Marsh K. Immunity to malaria: more questions than answers. Nat Immunol. 2008;9:725-32.

4. Hayakawa T, Culleton R, Otani H, Horii T, Tanabe K. Big bang in the evolution of extant malaria parasites. Mol Biol Evol. 2008;25:2233-9.

5. Warimwe GM, Murungi LM, Kamuyu G, Nyangweso GM, Wambua J, Naranbhai $V$, et al. The ratio of monocytes to lymphocytes in peripheral blood correlates with increased susceptibility to clinical malaria in Kenyan children. PLoS One. 2013;8:e57320

6. Beeson JG, Duffy PE. The immunology and pathogenesis of malaria during pregnancy. Curr Top Microbiol Immunol. 2005;297:187-227.

7. Ter Kuile FO, Terlouw DJ, Phillips-Howard PA, Hawley WA, Friedman JF, Kolczak MS, et al. Impact of permethrin-treated bed nets on malaria and allcause morbidity in young children in an area of intense perennial malaria transmission in western Kenya: cross-sectional survey. Am J Trop Med Hyg. 2003:68:100-7.

8. Rasti N, Wahlgren M, Chen Q. Molecular aspects of malaria pathogenesis. FEMS Immunol Med Microbiol. 2004;41:9-26

9. WHO: World Malaria Report. Geneva; 2014.

10. Good MF, Doolan DL. Malaria vaccine design: Immunological considerations. Immunity. 2010;33:555-66.

11. Nossal GJV. Vaccines of the future. Vaccine. 2011;29.

12. Fan L, Lee SY, Koay E, Harkensee C: Plasmodium knowlesi infection: A diagnostic challenge. BMJ Case Rep 2013, 2013. Da.

13. Cox-Singh J, Davis TME, Lee K-S, Shamsul SSG, Matusop A, Ratnam S, et al. Plasmodium knowlesi malaria in humans is widely distributed and potentially life threatening. Clin Infect Dis. 2008:46:165-71.

14. Cox-Singh J. Zoonotic malaria: Plasmodium knowlesi, an emerging pathogen. Curr Opin Infect Dis. 2012;25:530-6.

15. Reed KD, Meece JK, Henkel JS, Shukla SK. Birds, migration and emerging zoonoses: west nile virus, lyme disease, influenza $A$ and enteropathogens. Clin Med Res. 2003;1:5-12. 
16. De Meneghi D. Wildlife, environment and (re)-emerging zoonoses, with special reference to sylvatic tick-borne zoonoses in North-Western Italy. Ann Ist Super Sanita. 2006;42:405-9.

17. Mukaratirwa S, Foggin CM. Infectivity of Trichinella sp. isolated from Crocodylus niloticus to the indigenous Zimbabwean pig (Mukota). Int J Parasitol. 1999:29:1129-31.

18. Murrell KD, Pozio E. Worldwide Occurrence and Impact of Human Trichinellosis, 1986-2009. Emerg Infect Dis. 2011;17:2194-202.

19. Gottstein B, Pozio E, Nöckler K. Epidemiology, diagnosis, treatment, and control of trichinellosis. Clin Microbiol Rev. 2009;22:127-45.

20. Mukaratirwa S, La Grange L, Pfukenyi DM. Trichinella infections in animals and humans in sub-Saharan Africa: a review. Acta Trop. 2013;125:82-9.

21. La Grange LJ, Marucci G, Pozio E. Trichinella zimbabwensis in wild Nile crocodiles (Crocodylus niloticus) of South Africa. Vet Parasitol. 2009;161:88-91.

22. La Grange LJ, Marucci G, Pozio E. Trichinella zimbabwensis in a naturally infected mammal. J Helminthol. 2010;84:35-8.

23. La Grange LJ, Govender D, Mukaratirwa S, Hughes DM. The occurrence of Trichinella zimbabwensis in naturally infected wild crocodiles (Crocodylus niloticus) from the Kruger National Park, South Africa. Dev Change. 2012;32:1-6

24. Jackson JA, Friberg IM, Little S, Bradley JE. Review series on helminths, immune modulation and the hygiene hypothesis: immunity against helminths and immunological phenomena in modern human populations: coevolutionary legacies? Immunology. 2009;126:18-27.

25. Aide $\mathrm{P}$, Bassat $\mathrm{Q}$, Alonso PL. Towards an effective malaria vaccine. Arch Dis Child. 2007;92:476-9

26. Hartgers FC, Yazdanbakhsh M. Co-infection of helminths and malaria: Modulation of the immune responses to malaria. Parasite Immunol. 2006;28:497-506

27. Van Riet E, Hartgers FC, Yazdanbakhsh M. Chronic helminth infections induce immunomodulation: consequences and mechanisms. Immunobiology. 2007:212:475-90

28. Alving CR. Design and selection of vaccine adjuvants: animal models and human trials. Vaccine. 2002;20 Suppl 3:S56-64.

29. Alving CR, Peachman KK, Rao M, Reed SG. Adjuvants for human vaccines. Curr Opin Immunol. 2012;310-315.

30. Wipasa J, Elliott S, Xu H, Good MF. Immunity to asexual blood stage malaria and vaccine approaches. Immunol Cell Biol. 2002;80:401-14.

31. Schwartz L, Brown GV, Genton B, Moorthy VS. A review of malaria vaccine clinical projects based on the WHO rainbow table. Malar J. 2012;11.

32. Jones TR, Hoffman SL. Malaria Vaccine Development. Clin Microbiol Rev. 1994;7:303-10.

33. Abath FGC, Montenegro SML, Gomes YM. Vaccines against human parasitic diseases: An overview. Acta Trop. 1998;237-254.

34. Su Z, Segura M, Stevenson MM. Reduced protective efficacy of a blood-stage malaria vaccine by concurrent nematode infection. Infect Immun. 2006:74:2138-44

35. Su Z, Segura M, Morgan K, Loredo-Osti JC, Stevenson MM. Impairment of protective immunity to blood-stage malaria by concurrent nematode infection. Infect Immun. 2005;73:3531-9.

36. Harnett W. Secretory products of helminth parasites as immunomodulators. Mol Biochem Parasitol. 2014;1-7.

37. Shankarkumar U, Shankarkumar A, Ghosh K. HIV and malaria co-infection in Mumbai, western India. J Vector Borne Dis. 2011;48:155-8.

38. Boraschi D, Alemayehu MA, Aseffa A, Chiodi F, Chisi J, Del Prete G, et al. Immunity against HIV/AIDS, malaria, and tuberculosis during co-infections with neglected infectious diseases: Recommendations for the European Union research priorities. PLoS Negl Trop Dis. 2008;2.

39. Brooker S, Akhwale W, Pullan R, Estambale B, Clarke SE, Snow RW, et al. Epidemiology of Plasmodium-helminth co-infection in Africa: populations at risk, potential impact on anemia, and prospects for combining control. Am J Trop Med Hyg. 2007;77:88-98.

40. Mwangi TW, Bethony JM, Brooker S. Malaria and helminth interactions in humans: an epidemiological viewpoint. Ann Trop Med Parasitol. 2006;100:551-70.

41. Supali T, Verweij JJ, Wiria AE, Djuardi Y, Hamid F, Kaisar MMM, et al. Polyparasitism and its impact on the immune system. Int J Parasitol. 2010:40:1171-6.

42. Fenton $\mathrm{A}$, Knowles $\mathrm{SCL}$, Petchey $\mathrm{OL}$, Pedersen $\mathrm{AB}$. The reliability of observational approaches for detecting interspecific parasite interactions: comparison with experimental results. Int J Parasitol. 2014
43. Knowles SCL. The effect of helminth co-infection on malaria in mice: A metaanalysis. Int J Parasitol. 2011:41:1041-51.

44. Lyke KE, Dicko A, Dabo A, Sangare L, Kone A, Coulibaly D, et al. Association of Schistosoma haematobium infection with protection against acute Plasmodium falciparum malaria in Malian children. Am J Trop Med Hyg. 2005;73:1124-30

45. Bejon P, Mwangi TW, Lowe B, Peshu N, Hill AVS, Marsh K. Helminth infection and eosinophilia and the risk of Plasmodium falciparum malaria in 1- to 6-year-old children in a malaria endemic area. PLoS Negl Trop Dis. 2008;2.

46. Roussilhon C, Brasseur P, Agnamey P, Prignon JL, Druilhe P. Understanding human-Plasmodium falciparum immune interactions uncovers the immunological role of worms. PLoS One. 2010;5.

47. Nacher M. Interactions between worms and malaria: Good worms or bad worms? Malar J. 2011;10:259.

48. Taylor MD, van der Werf N, Maizels RM. T cells in helminth infection: the regulators and the regulated. Trends Immunol. 2012;33:181-9.

49. Segura M, Matte C, Thawani N, Su Z, Stevenson MM. Modulation of malariainduced immunopathology by concurrent gastrointestinal nematode infection in mice. Int J Parasitol. 2009:39:1525-32.

50. Brindley PJ, Mitreva M, Ghedin E, Lustigman S. Helminth genomics: The implications for human health. PLoS Negl Trop Dis. 2009:3.

51. Maizels RM, Pearce EJ, Artis D, Yazdanbakhsh M, Wynn TA. Regulation of pathogenesis and immunity in helminth infections. J Exp Med. 2009;206:2059-66.

52. Ashour DS. Trichinella spiralis immunomodulation: an interactive multifactorial process. Expert Rev Clin Immunol. 2013;9:669-75.

53. Nicoletti A. Toxocariasis. Handb Clin Neurol. 2013;114:217-28.

54. Fu C-J, Chuang T-W, Lin H-S, Wu C-H, Liu Y-C, Langinlur MK, et al. Seroepidemiology of Toxocara canis infection among primary schoolchildren in the capital area of the Republic of the Marshall Islands. BMC Infect Dis. 2014;14:261.

55. Blaga R, Gherman C, Cozma V, Zocevic A, Pozio E, Boireau P. Trichinella species circulating among wild and domestic animals in Romania. Vet Parasitol. 2009:159:218-21.

56. Girma S. Assessment of awareness on food borne zoonoses and its relation with veterinary public health services in and around Addis Ababa, Ethiopia. Ethiop Vet J. 2012;4.

57. Alemu A, Shiferaw Y, Ambachew A, Hamid H. Malaria helminth co-infections and their contribution for aneamia in febrile patients attending Azzezo health center, Gondar, Northwest Ethiopia: A cross sectional study. Asian Pac J Trop Med. 2012;5:803-9.

58. Despommier D, Gwadz R, Hotez JP, Knirsch AC. Parasitic Diseases. In: Parasit Dis. 5th ed. New York: Apple Trees productions; 2005. p. 363.

59. Mulcahy G, O'Neill S, Fanning J, McCarthy E, Sekiya M. Tissue migration by parasitic helminths - an immunoevasive strategy? Trends Parasitol. 2005;21:273-7.

60. Bruschi F, Chiumiento L. Trichinella inflammatory myopathy: host or parasite strategy? Parasit Vectors. 2011:4:42.

61. Stoltzfus RJ, Chwaya HM, Montresor A, Albonico M, Savioli L, Tielsch JM. Malaria, hookworms and recent fever are related to anemia and iron status indicators in 0- to 5-y old Zanzibari children and these relationships change with age. J Nutr. 2000;130:1724-33.

62. Ilic N, Gruden-Movsesijan A, Sofronic-Milosavljevic L. Trichinella spiralis: shaping the immune response. Immunol Res. 2012;52:111-9.

63. Maizels RM, Yazdanbakhsh M. Immune regulation by helminth parasites: cellular and molecular mechanisms. Nat Rev Immunol. 2003:3:733-44

64. Adisakwattana P, Nuamtanong S, Kusolsuk T, Chairoj M, Yenchitsomanas P-T, Chaisri U. Non-encapsulated Trichinella spp., T. papuae, diminishes severity of DSS-induced colitis in mice. Asian Pac J Allergy Immunol. 2013;31:106-14.

65. Fairlie-Clarke KJ, Lamb TJ, Langhorne J, Graham AL, Allen JE. Antibody isotype analysis of malaria-nematode co-infection: problems and solutions associated with cross-reactivity. BMC Immunol. 2010;11:6

66. Hoeve M a, Mylonas KJ, Fairlie-Clarke KJ, Mahajan SM, Allen JE, Graham AL. Plasmodium chabaudi limits early Nippostrongylus brasiliensis-induced pulmonary immune activation and Th2 polarization in co-infected mice. BMC Immunol. 2009;10:60.

67. Noland GS, Urban JF, Fried B, Kumar N. Counter-regulatory anti-parasite cytokine responses during concurrent Plasmodium yoelii and intestinal helminth infections in mice. Exp Parasitol. 2008;119:272-8. 
68. Gruden-Movsesijan A, Ilic N, Colic M, Majstorovic I, Vasilev S, Radovic I, et al. The impact of Trichinella spiralis excretory-secretory products on dendritic cells. Comp Immunol Microbiol Infect Dis. 2011;34:429-39.

69. Gruden-Movsesijan A, Ilic N, Mostarica-Stojkovic M, Stosic-Grujicic S, Milic M, Sofronic-Milosavljevic L. Trichinella spiralis: Modulation of experimental autoimmune encephalomyelitis in DA rats. Exp Parasitol. 2008;118:641-7.

70. Dupouy-Camet J. Presidential address of ICT12 Conference: "Trichinella and trichinellosis-A never ending story.". Vet Parasitol. 2009;159:194-6.

71. Onkoba, WN, Chimbari, MJ, Kamau, JK, Mukaratirwa, S: Serum cytokines, anti-Trichinella and anti-Plasmodium antibody responses in BALB/C mice mono- and co-infected with Trichinella zimbabwensis and Plasmodium berghei ANKA. Acta Trop. In press

72. McCall MBB, Sauerwein RW. Interferon- $\gamma$-central mediator of protective immune responses against the pre-erythrocytic and blood stage of malaria. J Leukoc Biol. 2010;88:1131-43.

73. Schlagenhauf P, Weld L, Goorhuis A, Gautret P, Weber R, von Sonnenburg F, et al. Travel-associated infection presenting in Europe (2008-12): an analysis of EuroTravNet longitudinal, surveillance data, and evaluation of the effect of the pre-travel consultation. Lancet Infect Dis. 2015;15:55-64.

74. Tappeh H, Manafi G, Asgharzadeh M, Manafi F: Incidence of Giardia lamblia Subspecies by PCR-RFLP in Stool Specimens of Hospitalized Children at Urmia Mutahhari Hospital, West Azerbaijan Province, Iran. 2014, 9:541-547.

75. Ramirez DJ, Heredia DR, Hernández C, León CM, Moncada IL, Reyes P, Pinila EA, Lopez CM: Molecular diagnosis and genotype analysis of Giardia duodenalis in asymptomatic children from a rural area in central Colombia. Infect Genet Evol 2015(March):1-6

76. Faubert G. Immune response to Giardia duodenalis. Clin Microbiol Rev. 2000;13:35-54.

77. Carrero JC, Cervantes-Rebolledo C, Aguilar-Díaz H, Díaz-Gallardo MY, Laclette $J \mathrm{P}$, Morales-Montor J. The role of the secretory immune response in the infection by Entamoeba histolytica. Parasite Immunol. 2007;29:331-8.

78. Andrews KT, Fisher G, Skinner-Adams TS. Drug repurposing and human parasitic protozoan diseases. Int J Parasitol Drugs Drug Resist. 2014:4:95-111.

79. Putignani L, Menichella D. Global distribution, public health and clinical impact of the protozoan pathogen cryptosporidium. Interdiscip Perspect Infect Dis. 2010;2010.

80. Wang L, Xue X, Li J, Zhou Q, Yu Y, Du A. Cryptosporidiosis in broiler chickens in Zhejiang Province, China: molecular characterization of oocysts detected in fecal samples. Parasite. 2014;21:36.

81. Meireles M. Cryptosporidium infection in Brazil: implications for veterinary medicine and public health. Rev Bras Parasitol Veterinária. 2010;2961:197-204

82. Adamu H, Petros B, Zhang G, Kassa H, Amer S, Ye J, et al. Distribution and clinical manifestations of Cryptosporidium species and subtypes in HIV/AIDS patients in Ethiopia. PLoS Negl Trop Dis. 2014;8, e2831.

83. Baroudi D, Khelef D, Goucem R, Adjou KT, Adamu H, Zhang H, et al. Common occurrence of zoonotic pathogen Cryptosporidium meleagridis in broiler chickens and turkeys in Algeria. Vet Parasitol. 2013;196:334-40.

84. Karp CL, Auwaerter PG. Coinfection with HIV and tropical infectious diseases. I. Protozoal pathogens. Clin Infect Dis. 2007:45:1208-13.

85. Macpherson CNL. Human behaviour and the epidemiology of parasitic zoonoses. Int J Parasitol. 2005;35:1319-31.

86. Hofstra N, Bouwman AF, Beusen AHW, Medema GJ. Exploring global Cryptosporidium emissions to surface water. Sci Total Environ. 2013;442:10-9.

87. Hofstra N. Quantifying the impact of climate change on enteric waterborne pathogen concentrations in surface water. Curr Opin Environ Sustain. 2011:3:471-9.

88. Robertson ID, Irwin PJ, Lymbery AJ, Thompson RCA. The role of companion animals in the emergence of parasitic zoonoses. Int J Parasitol. 2000;1369-1377.

89. Torgerson PR, Macpherson CNL. The socioeconomic burden of parasitic zoonoses: Global trends. Vet Parasitol. 2011;182:79-95.

90. Sacks D, Sher A. Evasion of innate immunity by parasitic protozoa. Nat Immunol. 2002;3:1041-7.

91. Fèvre EM, Wissmann BV, Welburn SC, Lutumba P. The burden of human African Trypanosomiasis. PLoS Negl Trop Dis. 2008;2.

92. Blum J, Schmid C, Burri C. Clinical aspects of 2541 patients with second stage human African trypanosomiasis. Acta Trop. 2006;97:55-64.

93. Kagira JM, Maina N, Njenga J, Karanja SM, Karori SM, Ngotho JM: Prevalence and types of coinfections in sleeping sickness patients in Kenya (2000/2009). J Trop Med 2011, 2011.
94. Kuepfer I, Hhary EP, Allan M, Edielu A, Burri C, Blum JA: Clinical presentation of T.b. rhodesiense sleeping sickness in second stage patients from Tanzania and Uganda. PLoS Negl Trop Dis 2011, 5.

95. Wangari N, Maina N, Nyeri A: Isolation, propagation and characterization of Trypanosoma brucei gambiense from Human African Trypanosomosis patients in south Sudan. Universitat Basel; 2006.

96. Nannyonga B, Mugisha JYT, Luboobi LSS. Does co-infection with malaria boost persistence of trypanosomiasis? Nonlinear Anal Real World Appl. 2012;13:1379-90.

97. Christensen NO, Furu P, Kurtzhals J, Odaibo A. Heterologous synergistic interactions in concurrent experimental infection in the mouse with Schistosoma mansoni, Echinostoma revolutum, Plasmodium yoelii, Babesia microti, and Trypanosoma brucei. Parasitol Res. 1988;74:544-51.

98. Renia L, Howland SW, Claser C, Gruner AC, Suwanarusk R, Teo T, et al. Cerebral Malaria: Mysteries at the blood-brain barrier. Virulence. 2012;3:193-201

99. Baptista FG, Pamplona A, Pena AC, Mota MM, Pied S, Vigário AM. Accumulation of Plasmodium berghei-infected red blood cells in the brain is crucial for the development of cerebral malaria in mice. Infect Immun. 2010;78:4033-9.

100. Kjemtrup AM, Conrad PA. Human babesiosis: an emerging tick-borne disease. Int J Parasitol. 2000;30:1323-37.

101. Hunfeld KP, Hildebrandt A, Gray JS. Babesiosis: Recent insights into an ancient disease. Int J Parasitol. 2008:38:1219-37.

102. Vannier E, Krause PJ. Update on babesiosis. Interdiscip Perspect Infect Dis. 2009;2009:984568.

103. Homer MJ, Aguilar-Delfin I, Telford SR, Krause PJ, Persing DH. Babesiosis. Clin Microbiol Rev. 2000;13:451-69.

104. Dvoraková HM, Dvorácková M. Babesiosis, a little known zoonosis. Epidemiol Mikrobiol Imunol. 2007:56:176-80.

105. Zhou X, Li S-G, Chen S-B, Wang J-Z, Xu B, Zhou H-J, et al. Co-infections with Babesia microti and Plasmodium parasites along the China-Myanmar border. Infect Dis poverty. 2013;2:24.

106. Krause PJ, Daily J, Telford SR, Vannier E, Lantos P, Spielman A. Shared features in the pathobiology of babesiosis and malaria. Trends Parasitol. 2007;23:605-10.

107. Blevins SM, Greenfield RA, Bronze MS. Blood smear analysis in babesiosis, ehrlichiosis, relapsing fever, malaria, and Chagas disease. Cleve Clin J Med. 2008;75:521-30.

108. Krause PJ. Babesiosis diagnosis and treatment. Vector Borne Zoonotic Dis. 2003;3:45-51.

109. Wormser GP, Wormser GP, Dattwyler RJ, Dattwyler RJ, Shapiro ED, Shapiro $E D$, et al. The clinical assessment, treatment, and prevention of lyme disease, human granulocytic anaplasmosis, and babesiosis: clinical practice guidelines by the Infectious Diseases Society of America. Clin Infect Dis. 2006:43:1089-134.

110. Vial HJ, Gorenflot A. Chemotherapy against babesiosis. Vet Parasitol. 2006;138:147-60

111. Gray J, Zintl A, Hildebrandt A, Hunfeld K-P, Weiss L. Zoonotic babesiosis: overview of the disease and novel aspects of pathogen identity. Ticks Tick Borne Dis. 2010;1:3-10.

112. Clark IA, Jacobson LS. Do babesiosis and malaria share a common disease process? Ann Trop Med Parasitol. 1998;92:483-8.

113. Na YJ, Chai J-Y, Jung B-K, Lee HJ, Song JY, Je JH, et al. An imported case of severe falciparum malaria with prolonged hemolytic anemia clinically mimicking a coinfection with babesiosis. Korean J Parasitol. 2014:52:667-72.

114. Vermeil C, Menut J, Miegeville M, Cruziat J, Julienne F, Morin O, Roger AP, Marjolet M, Bouillard C: Babesiasis, Pediatric Malaria: Does Confusion Exist in Africa? 1983 76:797-804.

115. Van Duivenvoorde LM, Voorberg-van der Wel A, van der Werff NM, Braskamp $\mathrm{G}$, Remarque EJ, Kondova I, et al. Suppression of Plasmodium cynomolgi in rhesus macaques by coinfection with Babesia microti. Infect Immun. 2010;78:1032-9.

116. Van den Bogaart E, Berkhout MMZ, Adams ER, Mens PF, Sentongo E, Mbulamberi DB, et al. Prevalence, features and risk factors for malaria co-infections amongst visceral leishmaniasis patients from Amudat hospital, Uganda. PLoS Negl Trop Dis. 2012;6.

117. Van den Bogaart E, Talha A-BA, Straetemans M, Mens PF, Adams ER, Grobusch $M P$, et al. Cytokine profiles amongst Sudanese patients with visceral leishmaniasis and malaria co-infections. BMC Immunol. 2014;15:16.

118. Kima PE. Leishmania molecules that mediate intracellular pathogenesis. Microbes Infect. 2014;16:8-13. 
119. Abdeladhim M, Kamhawi S, Valenzuela JG. What's behind a sand fly bite? The profound effect of sand fly saliva on host hemostasis, inflammation and immunity. Infect Genet Evol. 2014;28:691-703.

120. Guneratne R, Mendis D, Bandara T, Fernando SD. Toxoplasma, toxocara and tuberculosis co-infection in a four year old child. BMC Pediatr. 2011:11:44.

121. Kim K, Weiss LM. Toxoplasma: the next 100 years. Microbes Infect. 2008;10:978-84.

122. Jones JL, Kruszon-Moran D, Sanders-Lewis K, Wilson M. Toxoplasma gondii infection in the United States, 1999 2004, decline from the prior decade. Am J Trop Med Hyg. 2007:77:405-10.

123. Krueger WS, Hilborn ED, Converse RR, Wade TJ. Drinking water source and human Toxoplasma gondii infection in the United States: a cross-sectional analysis of NHANES data. BMC Public Health. 2014;14:711.

124. Marchioro AA, Colli CM, Ferreira EC, Viol BM, Araújo SM, FalavignaGuilherme AL. Risk factors associated with toxoplasmosis and toxocariasis in populations of children from nine cities in southern Brazil. J Helminthol. 2014;1-5.

125. Flegr J, Klapilová K, Kaňková S. Toxoplasmosis can be a sexually transmitted infection with serious clinical consequences. Not all routes of infection are created equal. Med Hypotheses. 2014;83:286-9.

126. Lalibert J, Carruthers VB. Host cell manipulation by the human pathogen Toxoplasma gondii. Cell Mol Life Sci. 2008;65:1900-15.

127. Ogendi E, Maina N, Kagira J, Ngotho M, Mbugua G, Karanja S. Questionnaire Survey on the Occurrence of Risk factors for Toxoplasma gondii infection amongst farmers in Thika district, Kenya. J S Afr Vet Assoc. 2013;84:1-6.

128. Chen J, Xu M-J, Zhou D-H, Song H-Q, Wang C-R, Zhu X-Q. Canine and feline parasitic zoonoses in China. Parasit Vectors. 2012;5:152.

129. Morrissette NS, Sibley LD. Cytoskeleton of apicomplexan parasites. Microbiol Mol Biol Rev. 2002;66:21-38. table of contents.

130. Andreani G, Lodge R, Richard D, Tremblay MJ. Mechanisms of interaction between protozoan parasites and HIV. Curr Opin HIV AIDS. 2012;7:276-82.

131. Abdi Al, Fegan G, Muthui M, Kiragu E, Musyoki JN, Opiyo M, et al. Plasmodium falciparum antigenic variation: relationships between widespread endothelial activation, parasite PfEMP1 expression and severe malaria. BMC Infect Dis. 2014;14:170.

132. Adams Y, Kuhnrae P, Higgins MK, Ghumra A, Rowe JA. Rosetting Plasmodium falciparum-infected erythrocytes bind to human brain microvascular endothelial cells in vitro, demonstrating a dual adhesion phenotype mediated by distinct $P$. falciparum erythrocyte membrane protein 1 domains. Infect Immun. 2014;82:949-59.

133. Hill D, Dubey JP. Toxoplasma gondii: Transmission, diagnosis, and prevention. Clin Microbiol Infect. 2002:8:634-40.

134. Castro-Filice LS, Barbosa BF, Angeloni MB, Silva NM, Gomes AO, Alves CMOS, et al. Azithromycin is able to control Toxoplasma gondii infection in human villous explants. J Transl Med. 2014;12:132.

135. Mustafa B, Michael GM, Esther KA, Hastings OS, Michael MI, Joshua MM, et al. Immunity to Plasmodium knowlesi $\mathrm{H}$ strain malaria in olive baboons. Int J Integr Biol. 2010;10:147-52.

136. Desai M, ter Kuile FO, Nosten F, McGready R, Asamoa K, Brabin B, et al. Epidemiology and burden of malaria in pregnancy. Lancet Infect Dis. 2007;7:93-104

137. Torrey EF, Yolken RH. Toxoplasma gondii and schizophrenia. Emerg Infect Dis. 2003;9:1375-80.

138. Da Silva RC, Langoni H. Toxoplasma gondii: Host-parasite interaction and behavior manipulation. Parasitol Res. 2009;105:893-8.

139. Onditi Fl, Nyamongo OW, Omwandho CO, Maina NW, Maloba F, Farah IO, et al. Parasite accumulation in placenta of non-immune baboons during Plasmodium knowlesi infection. Malar J. 2015;14:118.

140. Slater HC, Gambhir M, Parham PE, Michael E. Modelling co-infection with malaria and lymphatic filariasis. PLoS Comput Biol. 2013;9, e1003096.

141. Stensgaard A-S, Vounatsou P, Onapa AW, Simonsen PE, Pedersen EM, Rahbek $C$, et al. Bayesian geostatistical modelling of malaria and lymphatic filariasis infections in Uganda: predictors of risk and geographical patterns of coendemicity. Malar J. 2011;10:298.

142. Kelly-Hope LA, Molyneux DH, Bockarie MJ. Can malaria vector control accelerate the interruption of lymphatic filariasis transmission in Africa; capturing a window of opportunity? Parasit Vectors. 2013;6:39.

143. Cano J, Rebollo MP, Golding N, Pullan RL, Crellen T, Soler A, et al. The global distribution and transmission limits of lymphatic filariasis: past and present Parasit Vectors. 2014;7:466.
144. Graham AL, Lamb TJ, Read AF, Allen JE. Malaria-filaria coinfection in mice makes malarial disease more severe unless filarial infection achieves patency. J Infect Dis. 2005;191:410-21.

145. Tetsutani K, Ishiwata K, Ishida H, Tu L, Torii M, Hamano S, et al. Concurrent infection with Heligmosomoides polygyrus suppresses anti-Plasmodium yoelii protection partially by induction of CD4 + CD25 + Foxp3+ Treg in mice. Eur J Immunol. 2009;39:2822-30.

146. Fernández Ruiz D, Dubben B, Saeftel M, Endl E, Deininger S, Hoerauf A, et al. Filarial infection induces protection against $P$. berghei liver stages in mice. Microbes Infect. 2009;11:172-80.

147. Dolo H, Coulibaly YI, Dembele B, Konate S, Coulibaly SY, Doumbia SS, et al. Filariasis attenuates anemia and proinflammatory responses associated with clinical malaria: a matched prospective study in children and young adults. PLoS Negl Trop Dis. 2012;6:e1890.

148. Van der Werf N, Redpath SA, Azuma M, Yagita H, Taylor MD. Th2 Cell-Intrinsic Hypo-Responsiveness Determines Susceptibility to Helminth Infection. PLoS Pathog. 2013;9.

149. Bundy DAP, Walson JL, Watkins KL. Worms, wisdom, and wealth: why deworming can make economic sense. Trends Parasitol. 2013;29:142-8.

150. Njenga SM, Mwandawiro CS, Wamae CN, Mukoko DA, Omar AA, Shimada $M$, et al. Sustained reduction in prevalence of lymphatic filariasis infection in spite of missed rounds of mass drug administration in an area under mosquito nets for malaria control. Parasit Vectors. 2011;4:90.

151. Panda M, Sahoo PK, Mohapatra AD, Dutta S, Thatoi PK, Tripathy R, et al. Decreased prevalence of sepsis but not mild or severe $P$. falciparum malaria is associated with pre-existing filarial infection. Parasit Vectors. 2013;6:203.

152. Aliota MT, Chen C-CC, Dagoro H, Fuchs JF, Christensen BM. Filarial worms reduce Plasmodium infectivity in mosquitoes. PLoS Negl Trop Dis. 2011;5, e963.

153. Gillet M, Bresson-Hadni S. Hepatic alveolar echinococcosis. Rev Prat. 1991:41:1805-11.

154. Wandra T, Swastika K, Dharmawan NS, Purba IE, Sudarmaja IM, Yoshida T, et al. The present situation and towards the prevention and control of neurocysticercosis on the tropical island, Bali, Indonesia. Parasit Vectors. 2015;8:1-11.

155. Macpherson CN, Gottstein B, Geerts S. Parasitic food-borne and water-borne zoonoses. Rev Sci Tech. 2000;19:240-58.

156. Robertson ID, Thompson RC. Enteric parasitic zoonoses of domesticated dogs and cats. Microbes Infect. 2002;4:867-73.

157. Traub RJ, Robertson ID, Irwin PJ, Mencke N, Thompson RCAA. Canine gastrointestinal parasitic zoonoses in India. Trends Parasitol. 2005;21:42-8.

158. Pozio E, Owen IL, Marucci G, La Rosa G. Inappropriate feeding practice favors the transmission of Trichinella papuae from wild pigs to saltwater crocodiles in Papua New Guinea. Vet Parasitol. 2005;127:245-51.

159. Utzinger J, Bergquist R, Olveda R, Zhou XN. Important Helminth Infections in Southeast Asia. Diversity, Potential for Control and Prospects for Elimination. Adv Parasitol. 2010;72:1-30.

160. Saunders KA, Raine T, Cooke A, Lawrence CE. Inhibition of autoimmune type 1 diabetes by gastrointestinal helminth infection. Infect Immun. 2007;75:397-407.

161. Maizels RM, Hewitson JP, Smith KA. Susceptibility and immunity to helminth parasites. Curr Opin Immunol. 2012;24:459-66.

162. Kamuyu G, Bottomley C, Mageto J, Lowe B, Wilkins PP, Noh JC, et al. Exposure to Multiple Parasites Is Associated with the Prevalence of Active Convulsive Epilepsy in Sub-Saharan Africa. PLoS Negl Trop Dis. 2014;8.

163. Babalola O, Adu A, Akano A. Ocular cysticercosis in a 32 year old man in abuja ultrasonic features as an aid in diagnosis. Clin Ophthalmol. 2013;7:2275-9.

164. Elias FM, Martins MT, Foronda R, Jorge WA, De Araújo NS. Oral cysticercosis: case report and review of the literature. Rev Inst Med Trop Sao Paulo. 2005:47:95-8

165. Magwedere K, Hemberger MY, Hoffman LC, Dziva F. Zoonoses: a potential obstacle to the growing wildlife industry of Namibia. Infect Ecol Epidemiol. 2012;2.

166. Hotez PJ, Kamath A. Neglected tropical diseases in sub-saharan Africa: review of their prevalence, distribution, and disease burden. PLoS Negl Trop Dis. 2009;3, e412.

167. Mas-Coma S, Bargues MD, Valero MA. Fascioliasis and other plant-borne trematode zoonoses. Int J Parasitol. 2005;1255-1278.

168. Esteban JG, Gonzalez C, Curtale F, Muñoz-Antoli C, Valero MA, Bargues MD, et al. Hyperendemic fascioliasis associated with schistosomiasis in villages in the Nile Delta of Egypt. Am J Trop Med Hyg. 2003;69:429-37.

169. Keiser J, Utzinger J. Artemisinins and synthetic trioxolanes in the treatment of helminth infections. Curr Opin Infect Dis. 2007;20:605-12. 
170. Pedersen UB, Stendel M, Midzi N, Mduluza T, Soko W, Stensgaard A-S, et al. Modelling climate change impact on the spatial distribution of fresh water snails hosting trematodes in Zimbabwe. Parasit Vectors. 2014;7:1-12.

171. Mas-Coma S, Valero MA, Bargues MD. Climate change effects on trematodiases, with emphasis on zoonotic fascioliasis and schistosomiasis. Vet Parasitol. 2009;163:264-80.

172. Keiser J, Sayed H, El-Ghanam M, Sabry H, Anani S, El-Wakeel A, Hatz C, Utzinger J, el-Din SS, El-Maadawy W, Botros S: Efficacy and safety of artemether in the treatment of chronic fascioliasis in Egypt: Exploratory phase-2 trials. PLoS Negl Trop Dis 2011, 5.

173. Booth M, Graham A, Viney M. Parasitic co-infections: challenges and solutions. (Parasitic co-infections: challenges and solutions.). Parasitology. 2008;135:749.

174. Mulu A, Legesse M, Erko B, Belyhun Y, Nugussie D, Shimelis T, et al. Epidemiological and clinical correlates of malaria-helminth co-infections in Southern Ethiopia. Malar J. 2013;12:227.

175. Legesse M, Erko B, Balcha F. Increased parasitaemia and delayed parasite clearance in Schistosoma mansoni and Plasmodium berghei co-infected mice. Acta Trop. 2004;91:161-6.

176. Mulu A, Kassu A, Legesse M, Erko B, Nigussie D, Shimelis T, et al. Helminths and malaria co-infections are associated with elevated serum IgE. Parasit Vectors. 2014;7:240

177. Pearce EJ, Kane CM, Sun J, Taylor JJ, McKee AS, Cervi L. Th2 response polarization during infection with die helminth parasite Schistosoma mansoni. Immunol Rev. 2004;201:117-26.

178. Diallo TO, Remoue F, Gaayeb L, Schacht A-MM, Charrier N, De Clerck D, et al. Schistosomiasis coinfection in children influences acquired immune response against Plasmodium falciparum Malaria antigens. PLoS One. 2010;5:1-7.

179. Lemaitre M, Watier L, Briand V, Garcia A, Hesran J-YY LE, Cot M, et al Coinfection with Plasmodium falciparum and Schistosoma haematobium: Additional evidence of the protective effect of schistosomiasis on malaria in Senegalese children. Am J Trop Med Hyg. 2014;90:329-34.

180. Reilly L, Magkrioti C, Mduluza T, Cavanagh DR, Mutapi F. Effect of treating Schistosoma haematobium infection on Plasmodium falciparum-specific antibody responses. BMC Infect Dis. 2008:8:158

181. Florey LS, King CH, van Dyke MK, Muchiri EM, Mungai PL, Zimmerman PA, et al. Partnering parasites: Evidence of synergism between heavy Schistosoma haematobium and Plasmodium species infections in Kenyan children. PLoS Negl Trop Dis. 2012;6:1-11.

182. Nacher M. Worms and malaria: blind men feeling the elephant? Parasitology. 2008:135:861-8.

183. Nacher M. Worms and malaria: Noisy nuisances and silent benefits. Parasite Immunol. 2002;24:391-3.

184. Boel M, Carrara VI, Rijken M, Proux S, Nacher M, Pimanpanarak M, et al. Complex interactions between soil-transmitted helminths and malaria in pregnant women on the thai-burmese border. PLoS Negl Trop Dis. 2010;4

185. Sangweme DT, Midzi N, Zinyowera-Mutapuri S, Mduluza T, Diener-West M, Kumar N. Impact of schistosome infection on Plasmodium falciparum malariometric indices and immune correlates in school age children in burma valley, zimbabwe. PLoS Negl Trop Dis. 2010:4:7-11.

186. Imai N, Rujeni N, Nausch N, Bourke CD, Appleby LJ, Cowan G, et al. Exposure, infection, systemic cytokine levels and antibody responses in young children concurrently exposed to schistosomiasis and malaria. Parasitology. 2011;138:1519-33.

187. Noland GS, Graczyk TK, Fried B, Kumar N. Enhanced malaria parasite transmission from helminth co-infected mice. Am J Trop Med Hyg. 2007;76:1052-6.

\section{Submit your next manuscript to BioMed Central and take full advantage of:}

- Convenient online submission

- Thorough peer review

- No space constraints or color figure charges

- Immediate publication on acceptance

- Inclusion in PubMed, CAS, Scopus and Google Scholar

- Research which is freely available for redistribution 